\title{
Evidence for a circadian rhythm of insulin release from perifused rat pancreatic islets
}

\author{
E.Peschke, D.Peschke \\ Department of Anatomy and Cell Biology, Martin Luther University, Halle-Wittenberg, Germany
}

\begin{abstract}
Summary This study aims to analyse a circadian rhythm of insulin secretion from isolated rat pancreatic islets in vitro and its potential modulation by melatonin, the concentrations of which change in vivo inversely to that of insulin. The circadian rhythm was evaluated in a perifusion system, adapted to the specific conditions of pancreatic islets. To determine rhythmicity of insulin secretion, 30-min fractions were collected continuously for investigative periods of 44 to $112 \mathrm{~h}$. Insulin secretion in 10 experiments was analysed by using the MacAnova-program for period length $(\tau)$, the $\chi^{2}$-periodogram for test of significance $(p<0.001)$, and additionally the empirical cosine adaptation for amplitude and goodness-of-fit. Thereby a circadian pattern was observed with periods $(\tau)$ between 21.8 and $26.2 \mathrm{~h}$. The period duration (mean \pm SEM) was $23.59 \pm 0.503 \mathrm{~h}$, the overall mean insulin release $1038 \pm 13 \mathrm{pmol} / \mathrm{l}$ and the mean amplitude $88 \pm 17 \mathrm{pmol} / \mathrm{l}$. Adding melatonin (10 nmol/l,
\end{abstract}

$\mathrm{t}=2 \mathrm{~h}$ ) as a hormonal Zeitgeber during analysis of circadian insulin secretion phase-response studies show phase-shifts with approximately $9 \mathrm{~h}$ phase advance. Thereafter the circadian period was maintained, while the amplitude was enhanced. From this it is concluded that an endogenous circadian oscillator is located within the pancreatic islets of the rat that regulates circadian insulin secretion of the insulin-producing beta cells. The pacemaker is remarkably stable, because its periodicity is not affected by factors altering insulin secretion. In agreement with inhibitory influences of melatonin (range $0.5 \mathrm{nmol} / 1$ to $5 \mu \mathrm{mol} / \mathrm{l}$ ) on the insulin response in vitro, the phaseresponses support the contention that pancreatic beta cells may be targets for melatonin action. [Diabetologia (1998) 42: 1085-1092]

Keywords Pancreatic islets, circadian rhythm, insulin, melatonin, in vitro.
While there is strong evidence that circadian rhythms are generated in the mammalian suprachiasmatic nucleus (SCN) $[1,2]$ and in the avian pineal gland [3, 4], determinations of circadian rhythms in other isolated organs or cells are rare. Only few in vitro investigations of insect tissues or mammalian cells or organs such as intestine, adrenals [5-7], heart cell networks

Received: 11 December 1997 and in final revised form: 20 March 1998

Corresponding author: Dr. E. Peschke, Department of Anatomy and Cell Biology, Martin-Luther-University, Grosse Steinstrasse 52, D-06097 Halle/Saale, Germany

Abbreviations: SCN, suprachiasmatic nucleus; BSA, bovine serum albumin. and liver cells $[8,9]$ have shown the existence of circadian rhythms in culture $[10,11]$. In addition it has been shown that cultured mammalian retina possesses a genetically programmed circadian oscillator which regulates the synthesis of melatonin in this tissue. These observations suggest that all vertebrate photoreceptive structures synthesize melatonin under the control of circadian oscillators [12]. A circadian rhythm is an oscillation with a period duration of approximately $24 \mathrm{~h}$ (range 20 to $28 \mathrm{~h}$ ). Ultradian rhythms are oscillations with periods of less than $20 \mathrm{~h}$.

Various investigators have postulated oscillations of insulin secretion in a range of seconds [13] or periods between 9 and 14 min under both in vivo and in vitro conditions [14] or clonal pancreatic beta cells with periods of 5 to 8 min superimposed on 15 to 
20 min period fluctuations [15]. To date a circadian rhythm of insulin secretion has only been observed in vivo. Thus, in man a circadian rhythm of insulin secretion in vivo with increasing insulin secretion during the day and decreasing during the night has been described [16]. In this case, plasma-insulin and plasma-melatonin concentrations changed in an opposing manner during a 24-h period. In rats a circadian rhythm of the nuclear size of pancreatic beta cells with a peak at noon was demonstrated more than 40 years ago [17]. However, a circadian rhythm of insulin secretion from cultured mammalian pancreas islets is not known to date.

The aim of this study was to provide information about the dynamics of insulin secretion from isolated rat pancreatic islets maintained in an in vitro perifusion system. Because we had reason to suppose that a circadian rhythmicity of insulin secretion existed, attention was paid to the 24 -h profiles of in vitro insulin release.

\section{Materials and methods}

For islet preparation, 8 to 12 day-old Wistar rats of both sexes were used. The maternal animals were kept under standard environmental conditions [light: dark $=12: 12$, lights on at 06.00 hours; temperature $21 \pm 1{ }^{\circ} \mathrm{C}$; food: Altromin 1316 Altromin $\mathrm{GmbH}$ (Lage, Germany) and water ad libitum]. Animals were killed by decapitation (between 09.00 and 11.00 hours), the pancreas was removed and groups of three were transferred to a $5 \mathrm{ml}$ glass tube containing $1 \mathrm{mg} / \mathrm{ml}$ collagenase in $2 \mathrm{ml}$ ice cold Hanks' bovine serum albumin (BSA) (1 g/l BSA dissolved in Hanks' solution). The tube was shaken vigorously (about $4 \mathrm{~min}$ ) and then the suspension was transferred to $30 \mathrm{ml}$ ice cold Hanks' BSA solution. After sedimentation the islets were resuspended twice. Finally, the islets were collected with a glass capillary pipette under a dissection microscope. The time-span between pancreas-extirpation and the beginning of perifusion of the isolated islets was in a range of 50 to $60 \mathrm{~min}$.

Chemicals (purity p.a.) used were purchased either from Sigma Chemical Company, St. Louis, Mo., USA [medium-199 (5.6 mmol/1 glucose), BSA, Sephadex G-10, gentamicin, and melatonin] or from Serva, Heidelberg, Germany (collagenase). Trasylol was from Bayer AG (Leverkusen, Germany) and the other chemicals were obtained from Merck (Darmstadt, Germany). All solutions were made with pyrogen-free water prepared in a Barnstead EASYpure RF system (Barnstead/Thermolyne (Dubuque, Iowa, USA).

Perifusion of isolated rat pancreatic islets was performed as described earlier [42]. Briefly, about 300 isolated pancreatic islets were packed into a $6.6 \mathrm{~mm}$ glass column together with Sephadex G-10. The dead volume of the system was set to $1 \mathrm{ml}$. Medium-199 supplemented with $2.22 \mathrm{~g} / \mathrm{l}$ sodium hydrogen carbonate, $1.75 \mathrm{~g} / \mathrm{l} \mathrm{BSA}, 80 \mathrm{mg} / \mathrm{l}$ gentamicin and $3 \mathrm{mmol} / \mathrm{l}$ glucose was passed through the columns, at a flow rate of $1 \mathrm{ml} / 3 \mathrm{~min}$. The glucose concentration of the medium was always maintained at $8.6 \mathrm{mmol} / \mathrm{l}$ except where specifically noted. The medium was kept at $37^{\circ} \mathrm{C}$ and equilibrated with a mixture of $95 \%$ air and $5 \% \mathrm{CO}_{2}$. To clarify the vitality and to calculate the secretory capacity of the beta cells the experimental conditions were standardised with 3 min-exposures to $100 \mathrm{mmol} / \mathrm{l} \mathrm{KCl}$ and $50 \mathrm{mmol} / \mathrm{l}$ glucose at the end of each experiment. Expo- sure of the islets to $100 \mathrm{mmol} / \mathrm{l} \mathrm{KCl}$ induces a non-specific, dose-dependent insulin release of $1 \%$ of the total immunologically (RIA) detectable hormone content of the islets obtained with $10 \mathrm{mmol} / \mathrm{l} \mathrm{HCl}$. Exposure of the islets to $50 \mathrm{mmol} / \mathrm{l} \mathrm{glu}-$ cose (specific stimulus) induces an insulin release of $0.5 \%$. These stimulations for standardization of the perifusions are not shown in the figures. To determine rhythmicity of insulin secretion, $30 \mathrm{~min}$-fractions $(10 \mathrm{ml})$ were collected for 2 to 7 days (a total of 10 experiments). Additionally, for the phaseresponse studies $10 \mathrm{nmol} / \mathrm{l}$ melatonin, applied for $2 \mathrm{~h}$ as a hormonal Zeitgeber, was used. During the perifusion experiment the islets were illuminated continuously.

Insulin levels were measured by radioimmunoassay in $200 \mu \mathrm{l}$ of the collected sample using coat-a-count kits from DPC Biermann GmbH (Bad Nauheim, Germany). As standard, rat insulin (Novo BioLabs, Bagsvaerd, Denmark) was used in a 7-step dilution in a range from 43.25 to $8650 \mathrm{pmol} / \mathrm{l}$. The sensitivity limit of the assay was $43.25 \mathrm{pmol} / \mathrm{l}$. The intra-assay and inter-assay variations were 6.6 and $9.4 \%$, respectively.

Quantitative analysis of the perifusions results was carried out with a computer programe as described by V.J.Csernus and A. V.Schally [18]. The statistical calculations are based on the NET INT (net integral) values (the area under the curve) of the perifusion results. The MacAnova-Program (created by Ch. Bingham and G. Oehlert, University of Minnesota, School of Statistics) was used to analyse the period length $(\tau)$. The $\chi^{2}-$ periodogram (Chronobiological Kit by Stanford Software Systems, Stanford Calif., USA, with support of the Department of Zoology, University of Halle) was used to test for significance (limit: $p<0.001$ ). The empirical cosine adaptation was calculated to determine the amplitude and the goodness-of-fit of the insulin secretion rhythms with the following steps: removal of linear trend, fit of the cosine function to these values, comparison of the observed values (trend removed) with the fitted cosine values to calculate the coefficient of determination (calculations by A. Beckmann, University of Halle).

\section{Results}

The long-term investigations showed that insulin secretion from isolated pancreatic islets exhibited a rhythmic pattern (three examples are shown in Fig. 1). To analyse the rhythmicity of the insulin secretion, 30 min-fractions were collected continuously for 44 to $112 \mathrm{~h}$. Figure 2 shows the results of trend elimination (quadratic trend) using the time series data of the first example given in Figure 1. The period lengths of the insulin secretion rhythms in the 10 experiments ranged from 21.8 to $26.2 \mathrm{~h}$. All 10 experiments exhibited a circadian rhythm, 7 experiments show statistically significant circadian power expressions $(p<$ $0.001)$. The mean period duration (mean \pm SEM) was

Fig.1. Rhythmic pattern of insulin secretion from isolated pancreatic islets of neonate rats in vitro. Representative insulin secretory profiles ( 3 of 10 examples) during different investigation times is shown (experiment 1 to 3 , listed in Table 1 ). For radioimmunological insulin detection, media samples of the perifused islets were collected at 30 min intervals $(1 \mathrm{ml} /$ $3 \mathrm{~min}$ ). During the experiment (starting time: between 10.00 and 12.00 hours) the islets were illuminated continuously 

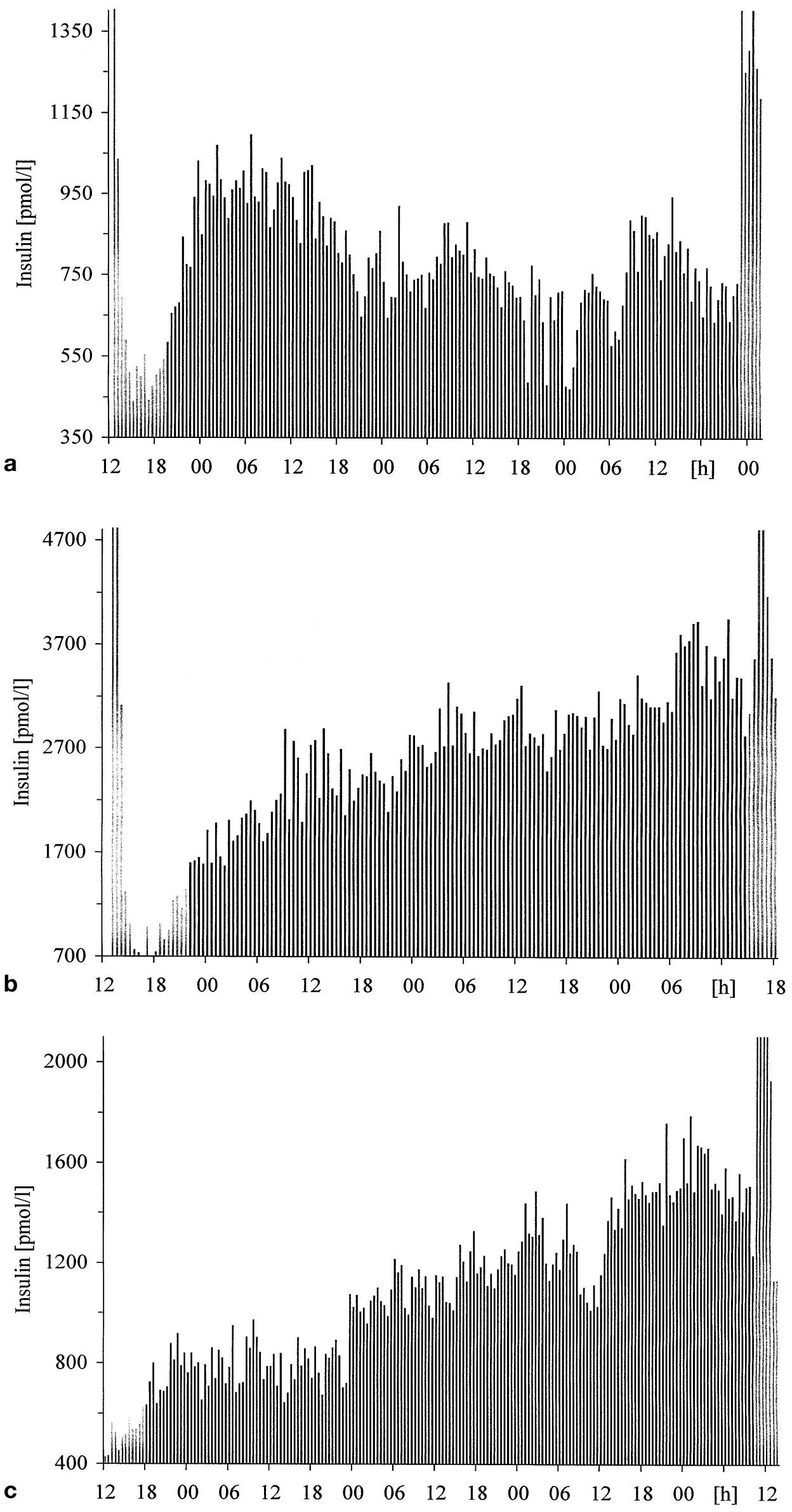


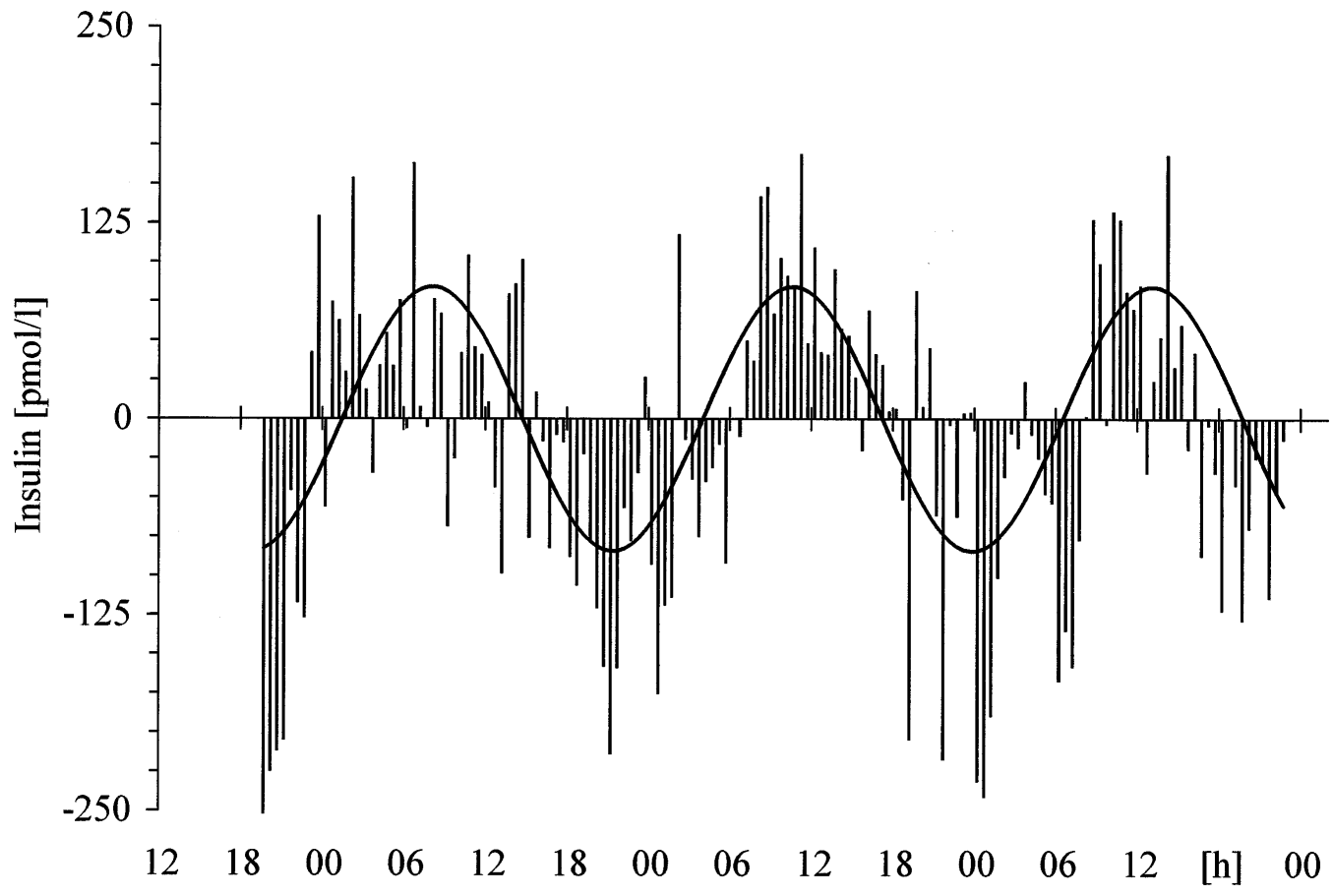

Fig. 2. Example of trend elimination (quadratic trend) obtained using the data of the time series shown in Figure 1 (experiment 1 , listed in Table 1). The curve is the best fit cosine function in comparison with the trend eliminated time series

$23.59 \pm 0.503 \mathrm{~h}$, the overall mean insulin release $1038 \pm 13 \mathrm{pmol} / \mathrm{l}$ and the mean amplitude $88 \pm$ $17 \mathrm{pmol} / \mathrm{l}$ (Table 1). The maxima of the insulin secretion were observed in the morning. Seasonal influences on the period length of the circadian rhythm was not perceptible. Ultradian and infradian oscillations were also found. The power expression, however, was lower in comparison to the circadian component (Fig. 3). The experimental protocol (30 min-fractions) was not able to record the well-established pulsatile oscillations with period lengths of only a few minutes.
To further characterise the circadian rhythm of insulin secretion obtained under in vitro conditions, we applied melatonin as a hormonal Zeitgeber, since this pineal secretory product is known to be involved in the control of the circadian timing under in vivo conditions (Fig. 4). The effect of $10 \mathrm{nmol} / 1$ melatonin, applied for $2 \mathrm{~h}$ at the maximum of the circadian insulin rhythm, provoked a $9 \mathrm{~h}$ phase advance (Fig.5). After the phase shift the circadian period was maintained and the amplitude was enhanced (from 92 to $155 \mathrm{pmol} / \mathrm{l})$.

\section{Discussion}

Insulin secretory rhythms of varying period lengths have been recorded both in vivo and in vitro. At present the mechanisms on which these rhythms are

Table 1. Circadian insulin secretion pulse characteristics in perifused neonate rat islets of 10 experiments

\begin{tabular}{|c|c|c|c|c|c|c|c|c|}
\hline \multirow{2}{*}{$\begin{array}{l}\text { Experiment } \\
\text { no. }\end{array}$} & \multirow{2}{*}{$\begin{array}{l}\text { Duration } \\
\text { (h) }\end{array}$} & \multirow[t]{2}{*}{ Samples } & \multirow{2}{*}{$\begin{array}{l}\text { Mean } \pm \text { SEM } \\
(\mathrm{pmol} / \mathrm{l})\end{array}$} & \multicolumn{2}{|l|}{ Amplitude } & \multirow{2}{*}{$\begin{array}{l}\text { Period lenght }(\tau) \\
\text { (h) }\end{array}$} & \multirow[t]{2}{*}{$p$ value } & \multirow{2}{*}{$\begin{array}{l}\text { Goodness- } \\
\text { of-fit (\%) }\end{array}$} \\
\hline & & & & $(\mathrm{pmol} / \mathrm{l})$ & $(\%)$ & & & \\
\hline 1 & 76 & 152 & $791 \pm 9$ & 97 & 12.25 & 26.20 & $p<0.001$ & 38.77 \\
\hline 2 & 65 & 130 & $2711 \pm 24$ & 164 & 6.04 & 22.10 & $p<0.001$ & 18.26 \\
\hline 3 & 89 & 178 & $1118 \pm 9$ & 67 & 6.04 & 22.20 & $p<0.001$ & 16.43 \\
\hline 4 & 112 & 224 & $1313 \pm 15$ & 156 & 11.86 & 23.50 & $p<0.001$ & 22.14 \\
\hline 5 & 60 & 120 & $734 \pm 11$ & 92 & 12.50 & 22.90 & $p<0.001$ & 29.06 \\
\hline 6 & 100 & 200 & $1950 \pm 25$ & 155 & 7.94 & 22.50 & $p<0.001$ & 9.31 \\
\hline 7 & 63 & 126 & $322 \pm 7$ & 44 & 13.82 & 26.00 & $p<0.001$ & 33.18 \\
\hline 8 & 88 & 176 & $517 \pm 11$ & 21 & 4.01 & 24.40 & NS & 7.17 \\
\hline 9 & 88 & 176 & $304 \pm 7$ & 16 & 5.39 & 24.30 & NS & 7.95 \\
\hline \multirow[t]{2}{*}{10} & 44 & 88 & $612 \pm 11$ & 66 & 10.74 & 21.80 & NS & 26.69 \\
\hline & & & $1038 \pm 13$ & $\begin{array}{l}\mathbf{8 8} \pm \mathbf{1 7} \\
(\text { mean } \pm \text { SEM })\end{array}$ & 9.06 & $\begin{array}{l}\mathbf{2 3 . 5 9} \pm \mathbf{0 . 5 0 3} \\
(\text { mean } \pm \text { SEM })\end{array}$ & & \\
\hline
\end{tabular}

Experiments were carried out in January (1 and 3), April (4-6, 10), May (2), July (7) and November (8 and 9) 

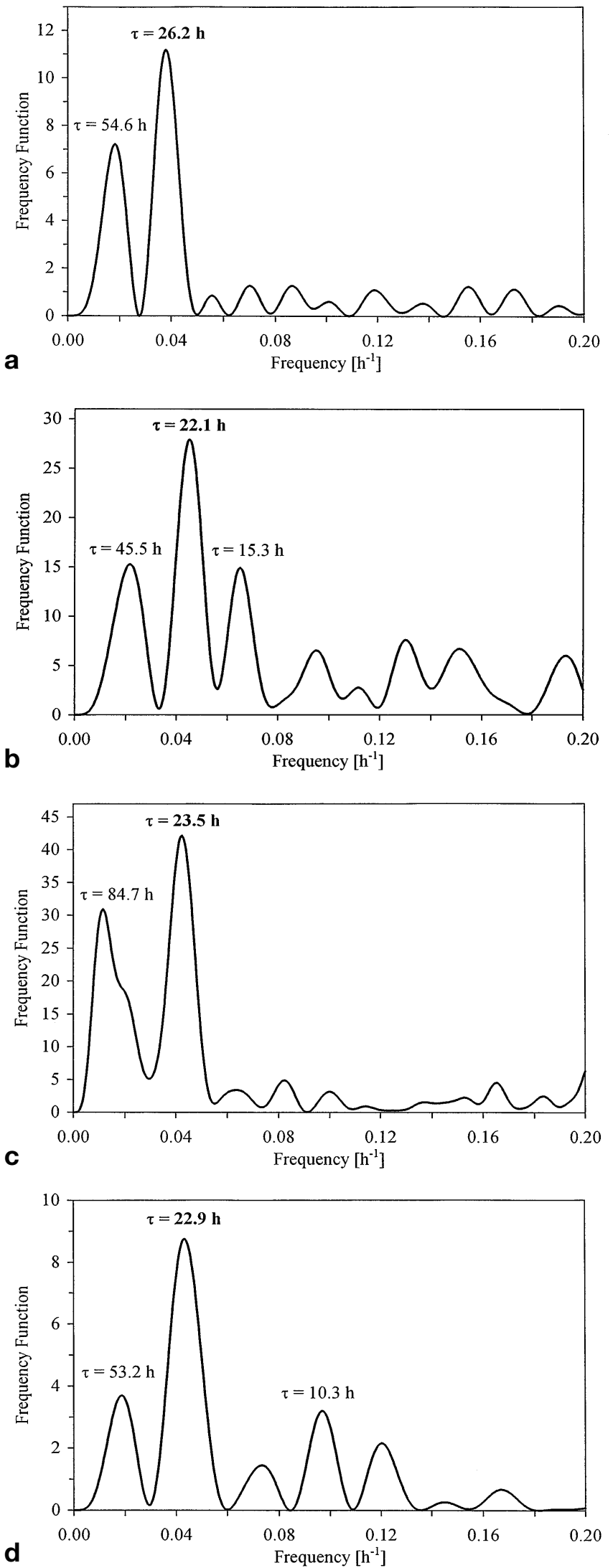

Fig.3. Four examples of the biomathematical evaluation using the MacAnova-program. Statistically significant circadian periods $(\tau)$ of insulin secretion with different period lengths are shown (experiment 1: $26.2 \mathrm{~h}$, experiment 2: $22.1 \mathrm{~h}$, experiment 4: $23.5 \mathrm{~h}$, experiment 5: $22.9 \mathrm{~h}$ ) based are not known. The high-frequency rhythms of the insulin secretion, for which the terms pulsatile or ultradian oscillations are used, have period lengths ranging from seconds to several minutes (5 to $20 \mathrm{~min}$ ) or to a few hours (e.g. 75 to $115 \mathrm{~min}$ or longer). Numerous publications and reviews have described these high-frequency oscillations of insulin release $[13,14,19-21]$. The current opinion is that they are generated by a pacemaker located within the pancreas. Observations made on decentralised islets of dogs [22], mice [23], rats [24, 25] and humans [21] strengthen this supposition. Additionally, autonomic blockade with atropine (cholinergic) or propranolol and dibenzyline (adrenergic) did not influence these pulsatile oscillations. Therefore it was suggested that the generation of these oscillations is not caused by the classical autonomic innervation of the islets, but that the intrapancreatic ganglion system could serve as the pacemaker $[26,27]$. It may be that the pacemaker co-ordinates the islets using the peptidergic nervous system [22]. In addition investigations on the recipients of pancreas transplants showed that both pulsatile and ultradian rhythms of the insulin secretion were dependent on the intrinsic innervation [28]. Influences of glucose concentrations and cyclic AMP mediated mechanisms on these oscillations have also been postulated [29] and investigations in humans have confirmed these findings [13].

More recent experiments on the rat carried out by Longo et al. [30] suggest that pulsatile insulin secretion is a basic property of the beta cell, and is caused by periodic fluctuations of intracellular calcium and metabolic activity. These results were complemented by findings showing that also a glucose-induced increase of cytoplasmic $\mathrm{Ca}^{2+}$ concentration in isolated somatostatin producing delta cells is often realised as oscillation [31]. It was postulated that an electrical coupling between delta cells and beta cells exists which caused the agreement between the oscillatory responses of somatostatin and insulin [32]. Spontaneous rhythmic activity generated by $\mathrm{Ca}^{2+}$ oscillations was also observed in the alpha cells [33]. These results indicate that each of the cell types mentioned above (beta cells as well as delta cells and alpha cells) is provided with intrinsic oscillatory activity.

Our results show that insulin secretion from the beta cells not only exhibits ultradian rhythms but also a circadian rhythm. These results are consistent with circadian rhythms in various organs in vitro. Moreover, the results are supported by Bünning [34], who observed a circadian contraction rhythm of isolated bowels from Mesocricetus auratus and postulated that endogenous daily periodic processes must exist for many organs without central control.

It is known that melatonin influences the central circadian pacemaker, SCN, and timedependently can reset the circadian clock in vitro [35]. Results indicated additionally that melatonin influences the electri- 


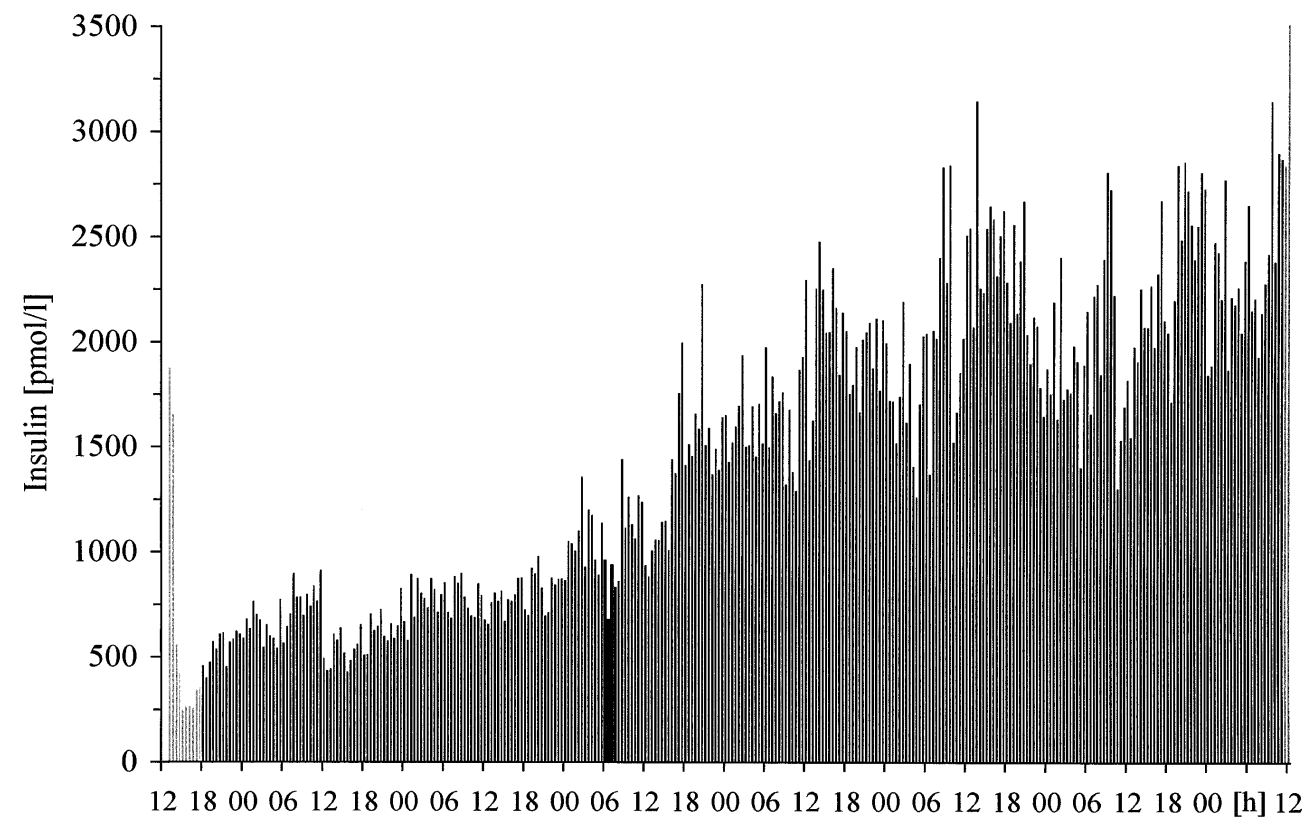

Fig. 4. Rhythmic pattern of insulin secretion in isolated pancreatic islets of neonate rats under long-term conditions ( 7 days) in vitro. The experimental protocol was the same as described in Figure 1. However, in this case after $60 \mathrm{~h}, 10 \mathrm{nmol} / 1$ melatonin was applied for $2 \mathrm{~h}$ (dark columns)

Fig.5. Results of trend elimination (linear trend) obtained using the data of the time series shown in Figure 4. The curves (continuous lines) indicate the Zeitgeber function of melatonin. The $2 \mathrm{~h}$ application of $10 \mathrm{nmol} / \mathrm{l}$ melatonin applied approximately at the maximum of the circadian oscillation $(\tau=$ $22.9 \mathrm{~h}$ ) caused a phase advance of around $9 \mathrm{~h}$. After this the circadian period was maintained $(\tau=22.5 \mathrm{~h})$; however, the amplitude was enhanced (from 92 to $155 \mathrm{pmol} / \mathrm{l}$ ). To heighten the visualization of the phase shift, the hypothetic location of the curves (dotted lines) has been drawn before and after melatonin application cal activity rhythms of SCN neurons and causes phase advances in a time-dependent manner [36].

Numerous investigations have shown that melatonin receptors exist on neurons of the SCN. They are coupled to G-proteins mediating the inhibitory influences of melatonin on cyclic nucleotides [37]. Putative melatonin receptors have also been shown in other neural structures as well as in non-neural organs of various systems [38]. Furthermore, it was suggested that melatonin is not only able to bind to membrane receptors but also to nuclear proteins [39] and to calmodulin [40]. Regarding pancreatic islets, melatonin binding sites have not yet been described. One can assume that the pancreatic islets of the rat are targets for melatonin because of the action of melatonin reported here, as well as the inhibitory

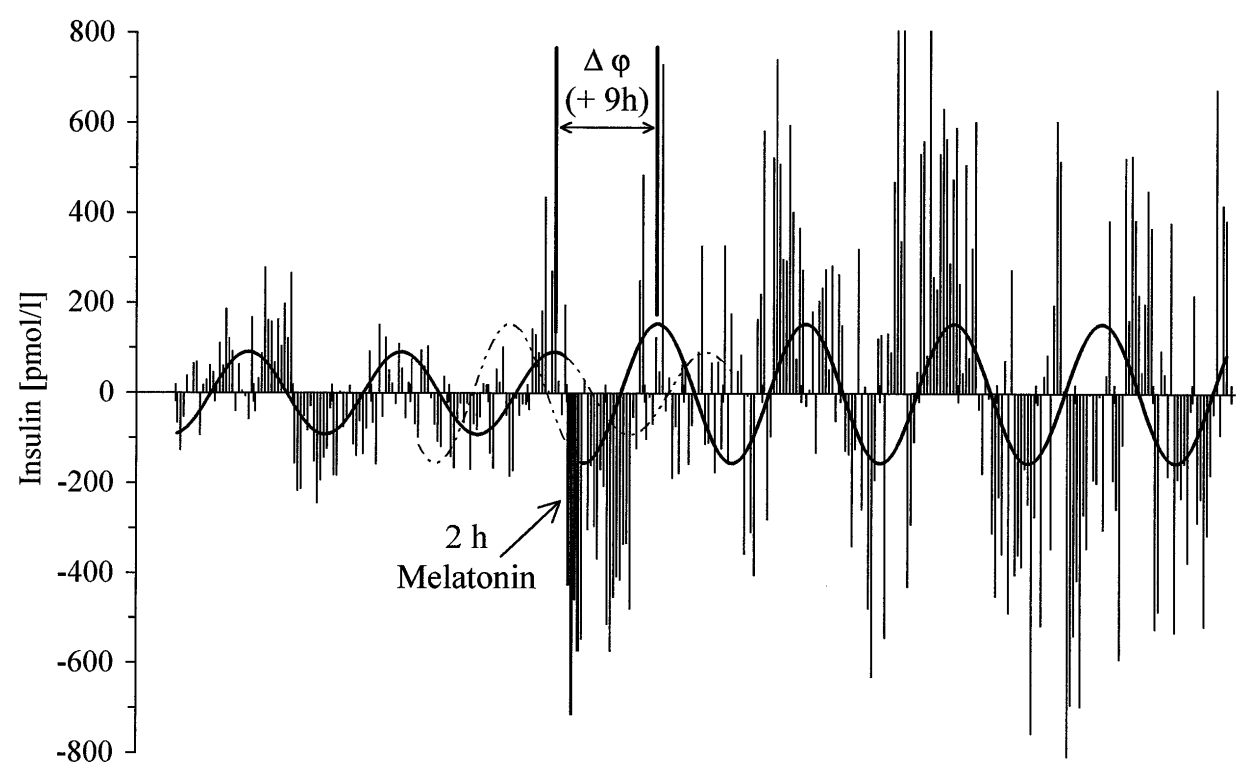


effects of melatonin on insulin secretion from pancreatic rat islets in vitro reported previously [41, 42]. Our results indicate that melatonin, as a hormonal Zeitgeber, influences the circadian rhythm of insulin release under in vitro conditions causing phase advances. Further investigations are needed both to elucidate the mechanisms of signal transduction and the sites of intracellular actions of melatonin in the islet and to clarify what happens to the rhythm if secretion is inhibited by other substances.

In conclusion we found that (i) insulin secretion from isolated pancreatic rat islets exhibits a circadian rhythm which is apparently generated within the islet and that (ii) the pineal secretory product melatonin influenced the rhythm generating oscillator and induced a phase shift in insulin secretion.

Acknowledgements. This study was supported by the DPC Biermann GmbH, Bad Nauheim, Germany. Additionally, the authors would like to thank both Ms. Uta Engelhardt for her skillful technical assistance and Ms. Susan Luginsland for proof-reading the English of the manuscript. Additionally, we thank Andreas Beckmann for assisting with the statistical analyses.

\section{References}

1. Moore RY (1983) Organization and function of a central nervous system circadian oscillator: The suprachiasmatic nucleus. Fed Proc 42: 2783-2789

2. Belenky M, Wagner S, Yarom Y, Matzner H, Cohen S, Castel M (1996) The suprachiasmatic nucleus in stationary organotypic culture. Neuroscience 1: 127-143

3. Binkley SA, Riebman JB, Reilly KB (1978) The pineal gland: a biological clock in vitro. Science 202: 1198-1200

4. Ghosh M, Csernus V, Mess B (1994) In vitro melatonin secretion pattern of the avian pineal gland with special reference to light reactivity. Neuroendocrinol Lett 16: 195-200

5. Unger F, Halberg F (1962) Circadian rhythm in the in vitro response of mouse adrenal to adrenocorticotropic hormone. Science 137: 1058-1060

6. Andrews RV (1971) Circadian rhythms in adrenal organ cultures. Morph J 117: 89-98

7. Shiotsuka R, Jovonovich J, Jovonovich J (1974) Circadian and ultradian corticosterone rhythms in adrenal organ cultures. Chronobiologia 1 [Suppl 1]: 109-121

8. Hardeland R (1973) Circadian rhythmicity in cultured liver cells. I. Rhythms in tyrosine aminotransferase activity and inducibility and in $\left[{ }^{3} \mathrm{H}\right]$ leucine incorporation. Int $\mathrm{J}$ Biochem 4: 581-590

9. Hardeland R (1973) Circadian rhythmicity in cultured liver cells. II. Reinduction of rhythmicity in tyrosine aminotransferase activity. Int J Biochem 4: 591-595

10. Rensing L (1970) Die circadiane Rhythmik von Zellen in vitro. Zool Anz [Suppl] 33: 166-171

11. Kadle R, Folk GE (1983) Importance of circadian rhythms in animal cell culture. Comp Biochem Physiol 76A: 773-776

12. Tosini G, Menaker M (1996) Circadian rhythms in cultured mammalian retina. Science 272: 419-421

13. Hellman B, Gylfe E, Bergstein P et al. (1994) Glucose induces oscillatory $\mathrm{Ca}^{2+}$ signalling and insulin release in human pancreatic beta cells. Diabetologia 37 [Suppl 2]: $11-20$
14. Weigle DS (1987) Pulsatile secretion on fuel-regulatory hormones. Diabetes 36: 764-775

15. Cunningham BA, Deeney JT, Bliss CR, Corkey BE, Tornheim K (1996) Glucose-induced oscillatory insulin secretion in perifused rat pancreatic islets and clonal $\beta$-cells (HIT). Am J Physiol 271: E702-E710

16. Boden G, Ruiz J, Urbain JL, Chen X (1996) Evidence for a circadian rhythm of insulin secretion. Am J Physiol 271: E246-E252

17. Hellman B, Hellerstrom C (1995) Diurnal changes in the function of the pancreatic islets of rats as indicated by nuclear size in the islet cells. Acta Endocrinol 31: 267-281

18. Csernus VJ, Schally AV (1991) The dispersed cell superfusion system. In: Greenstein BD (ed) Neuroendocrine research methods. Harwood Academic Publishers, London, pp 71-109

19. Lefèbvre PJ, Paolisso G, Scheen AJ, Henquin JC (1987) Pulsatility of insulin and glucagon release: physiological significance and pharmacological implications. Diabetologia 30: 443-452

20. Sturis J, Van Cauter E, Blackman JD, Polonsky KS (1991) Entrainment of pulsatile insulin secretion by oscillatory glucose infusion. J Clin Invest 87: 439-445

21. Marchetti P, Scharp DW, McLear M et al. (1994) Pulsatile insulin secretion from isolated human pancreatic islets. Diabetes 43: 827-830

22. Stagner JI, Samols E, Weir GC (1980) Sustained oscillations of insulin, glucagon, and somatostatin from the isolated canine pancreas during exposure to a constant glucose concentration. J Clin Invest 65: 939-942

23. Opara EC, Go VL (1991) Effect of nerve blockade on pulsatile insulin and glucagon secretion in vitro. Pancreas 6: 653-658

24. Bergstrom RW, Fujimoto WY, Teller DC, De Haën C (1989) Oscillatory insulin secretion in perifused isolated rat islets. Am J Physiol 257: E479-E485

25. Chou HF, Berman N, Ipp E (1994) Evidence for pancreatic pacemaker for insulin oscillations in low-frequency range. Am J Physiol 266: R1786-R1791

26. Stagner JI, Samols E (1985) Perturbation of insulin oscillations by nerve blockade in the in vitro canine pancreas. Am J Physiol 248: E516-E521

27. Stagner JI, Samols E (1985) Role of intrapancreatic ganglia in regulation of periodic insular secretion. Am J Physiol 248: E522-E530

28. Sonneberg GE, Hoffman RG, Johnson CP, Kissebah AH (1992) Low- and highfrequency insulin secretion pulses in normal subjects and pancreas transplant recipients: role of extrinsic innervation. J Clin Invest 90: 545-553

29. Chou HF, Ipp E (1990) Pulsatile insulin secretion in isolated rat islets. Diabetes 39: 112-117

30. Longo EA, Tornheim K, Deeney JT et al. (1991) Oscillations in cytosolic free $\mathrm{Ca}^{2+}$, oxygen consumption and insulin secretion in glucose stimulated rat pancreatic islets. J Biol Chem 266: 9314-9319

31. Berts A, Ball A, Dryselius S, Gylfe E, Hellman B (1996) Glucose stimulation of somatostatin-producing islet cells involves oscillatory $\mathrm{Ca}^{2+}$ signaling. Endocrinology 137: 693-697

32. Hellman B, Gylfe E, Bergsten P et al. (1994) The role of $\mathrm{Ca}^{2+}$ in the release of pancreatic islet hormones. Diabete Metab 20: 123-131

33. Berts A, Gylfe E, Hellman B (1997) Cytoplasmic $\mathrm{Ca}^{2+}$ in glucagon-producing pancreatic alpha-cells exposed to carbachol and agents affecting $\mathrm{Na}^{+}$fluxes. Endocrine 6: 79-83 
34. Bünning E (1958) Das Weiterlaufen der ,physiologischen Uhr" im Säugerdarm ohne zentrale Steuerung. Naturwissenschaften 45: 68

35. McArthur AJ, Gillette MU, Prosser RA (1991) Melatonin directly resets the rat suprachiasmatic circadian clock in vitro. Brain Res 565: 158-161

36. Guardiola-Lemaitre B (1994) Melatonin agonist/antagonist: from the receptor to therapeutic applications. Adv Pineal Res 8: 333-348

37. Reuss S (1996) Components and connections of the circadian timing system. Cell Tiss Res 258: 353-378

38. Shiu SYW, Chow PH, Yu ZH, Tang F, Pang SF (1996) Autoradiographic distribution and physiological regulation of $2-[125]$ iodomelatonin binding in rat epididymis. Life Sci 59: $1165-1174$
39. Acuna-Castroviejo D, Reiter RJ, Menendez-Pelaez A, Pablos MI, Burgos A (1994) Characterization of high-affinity melatonin binding sites in purified cell nuclei of rat liver. $\mathrm{J}$ Pineal Res 16: 100-112

40. Benitez-King G, Rios A, Martinez A, Anton-Tay F (1996) In vitro inhibition of $\mathrm{Ca}^{2+} /$ calmodulin-dependent kinase II activity by melatonin. Biochim Biophys Acta 1290: 191-196

41. Bailey CJ, Atkins TW, Matty AJ (1974) Melatonin inhibition of insulin secretion in the rat and mouse. Horm Res 5: 21-28

42. Peschke E, Peschke D, Hammer T, Csernus V (1997) Influence of melatonin and serotonin on glucose-stimulated insulin release from perifused rat pancreatic islets in vitro. $\mathbf{J}$ Pineal Res 23: 156-163 